\title{
Online Privacy Concerns Of Indian Consumers
}

\author{
Soumava Bandyopadhyay, Lamar University, USA
}

\begin{abstract}
This paper describes an empirical study that investigates the factors that influence consumers' online privacy concerns and their outcomes in the rapidly growing Indian online market. Indian consumers' online privacy concerns are found to be positively impacted by their perceived vulnerability to unauthorized gathering and use of personal information, and negatively impacted by their perceived ability to control the manner in which their personal information is collected and used online. The consumers' perceived vulnerability is negatively affected by their level of Internet literacy and their perceived ability to control the collection and use of information. In turn, the perceived ability to control information collection and use is positively influenced by both the Internet literacy level and the social awareness of the consumer. The privacy concerns of Indian consumers are found to negatively impact both their willingness to provide personal information to Websites, and their willingness to engage in e-commerce transactions. The implications of the findings for Websites targeting the Indian audience are discussed.
\end{abstract}

Keywords: Online privacy; information privacy; e-commerce; India

\section{INTRODUCTION}

ndia currently has about 81 million Internet users (Internet World Stats, 2010). This represents a 1,520\%
growth over the last 10 years and, considering that just under 7 percent of India's 1.17 billion people
currently use the Internet, the future growth potential is tremendous. More businesses are targeting Indian customers for e-commerce transactions in different product and service categories, from books, music and clothes, to computers and travel. In addition, over 18 million Indians actively participate in social media Websites, such as Orkut, Facebook, and Twitter (Patel, Vescovi, and Rocca, 2010; Sheth, 2008). Along with the increase in Internet usage by Indian consumers, there is a growing concern about online privacy protection. Invasion of online privacy involves the unauthorized collection, disclosure, or other use of personal information (Wang, Lee, and Wang, 1998). Consumers find it virtually impossible to transact business online without revealing personal information (Rust, Kannan, and Peng, 2002). Personal information is also often asked for when consumers are required to register at Websites before being able to browse free content. In addition, consumers' personal information could be obtained involuntarily by the use of cookies that track people's online surfing behavior. Vast amounts of information can be thus collected over the Internet, and digital networks can link all this private information in databases (Caruso, 1998). This information can then be bought, sold, and traded, possibly without the consumers' permission, which increases consumers' concerns regarding having to reveal personal information online, and regarding the way in which such information might be used (Fletcher, 2003). Such concerns range from the intrusion of one's privacy and being targeted with unsolicited advertisements, to potential hassles resulting from online identity theft.

The online privacy concerns of Indian consumers are likely to be compounded by the relatively weak privacy laws in India (Basu, 2010). The Information Technology Act of 2000, and the subsequent Information Technology (Amendment) Act of 2008 grant legal sanction to online surveillance, monitoring, and identification of data by government agencies, thus reducing Internet privacy. At the same time, there are no robust provisions for protecting the privacy rights of Internet users from potentially unauthorized gathering and use of information by private parties (Gupta, 2010). If Internet users get increasingly concerned about online privacy, the consequences could range from their declining to provide personal information online to the outright rejection of e-commerce, or even minimizing the use of the Internet (Nam et. al., 2006; Dinev and Hart, 2006a). 
Against this backdrop, we report an empirical study in this paper, which investigates the factors that impact the online privacy concerns of Indian consumers, and the possible outcomes of such concerns. A set of hypotheses is developed and tested in the Indian context. The managerial implications in terms of reducing consumers' online privacy concerns and encouraging e-commerce are also discussed.

\section{FACTORS AFFECTING ONLINE PRIVACY CONCERNS}

Two major factors that have been identified in the literature as major influencers of online privacy concerns are: 1) the consumers' perceived vulnerability to the unauthorized gathering and misuse of personal information; and 2) the consumers' perceived ability to control the manner in which personal information is collected and used (Dinev and Hart, 2004). Perceived vulnerability describes the perceived potential risk when personal information is revealed (Raab and Bennett, 1998). The revelation of private information could be caused by many factors, such as accidental disclosure, unauthorized access, hacking into networks, etc. (Rindfleish, 1997). The possible negative consequences for consumers include identity theft (Saunders and Zucker, 1999), undesirable consumer profiling (Budnitz, 1998), and being targeted by unwanted advertising messages on the Internet (i.e., 'spam' e-mails). These factors contribute to consumers feeling increasingly vulnerable to the risk of misuse of their private information on the Internet and, therefore, experiencing increased online privacy concerns (Dinev and Hart, 2004). The perceived ability to control is the extent to which consumers think they can prevent personal information from being disclosed online (Culnan and Armstrong, 1999). Consumers tend to think that information disclosure is less invasive to their privacy, and less likely to lead to negative consequences when they believe that they can control when and how such information is disclosed and used in the future. Hence, consumers' online privacy concerns are likely to be reduced by their perceived ability to control information collection and dissemination.

There is also a likely relationship between the perceived ability to control personal information collection and usage, and the perceived vulnerability to information misuse. If consumers feel that they can actually control how their private information is collected and used by Websites, they will also feel less vulnerable to the potential negative outcomes of information misuse. Therefore, perceived ability to control private information flow on the part of consumers will reduce their perceived vulnerability and, in turn, will reduce their online privacy concerns.

The preceding discussion leads to our first three research hypotheses:

H1: Indian consumers' perceived vulnerability to unauthorized online data collection and use of such data is positively related to their online privacy concerns.

H2: Indian consumers' perceived ability to control the manner in which their personal information is collected and used online is negatively related to their online privacy concerns.

H3: Indian consumers' perceived ability to control the manner in which their personal information is collected and used online is negatively related to their perceived vulnerability to unauthorized online personal data collection and use of such data.

Dinev and Hart (2006a) proposed the role of Internet literacy and social awareness in influencing consumers' online privacy concerns. Internet literacy refers to the level of skill and knowledge possessed by consumers in using the Internet, including establishing an Internet connection, navigating the Web, completing ecommerce transactions, protecting the computer from viruses and spyware, setting the browser's privacy and security options appropriately, and protecting one's privacy by employing adequate measures before disclosing information online (Dinev and Hart, 2006a; Spiekermann, Grossklags, and Berendt, 2001). In the context of our research, social awareness is described as the extent to which consumers are knowledgeable about the social issues involving Internet usage (Dinev and Hart, 2006a), such as trust, privacy, security, governance, censorship, and restrictions (Burn and Loch, 2001; Papazafeiropoulou and Pouloudi, 2001). Social awareness requires raised interest and passive involvement in these social issues, and is a key in increasing consumer consciousness (Bickford and Reynolds, 2002). Consumers who are socially aware will be interested in and follow community and government policies and initiatives related to technology and the Internet. Because of their interest in social issues and policy, consumers with a high degree of social awareness will closely follow Internet privacy issues and the development of privacy policies and regulations (Dinev and Hart, 2006a). 
Based on the above observations, we propose the following four hypotheses in the Indian context:

H4: Indian consumers' Internet literacy level is negatively related to their perceived vulnerability to unauthorized online personal data collection and use of such data.

H5: Indian consumers' social awareness level is positively related to their perceived vulnerability to unauthorized online personal data collection and use of such data.

H6: Indian consumers' Internet literacy level is positively related to their perceived ability to control the manner in which their personal information is collected and used online.

H7: Indian consumers' social awareness level is positively related to their perceived ability to control the manner in which their personal information is collected and used online.

\section{OUTCOMES OF ONLINE PRIVACY CONCERNS}

Increased consumer concerns about online information privacy is likely to affect all Internet-based activities that could result in the collection and subsequent use of personal data. When consumers perceive that negative consequences could result from submitting personal data online, they are less likely to do so (Nam et al., 2006). At the minimal level, consumers who are concerned about their online privacy will be unwilling to disclose personal information to Websites (Nam et al., 2006). This may result in browsing only those Websites where no personal data is captured (Rice, McCreadie, and Chang, 2001), or providing only limited and anonymous, or even false personal information to Websites (Dinev and Hart, 2006b) that require "registration" prior to using content. Consumers with elevated online privacy concerns could be unwilling to make e-commerce transactions altogether, since almost all such transactions require the disclosure of sensitive personal information, such as credit card numbers, telephone numbers, e-mail and postal addresses, etc. (Dinev and Hart, 2006a). Graeff and Harmon (2002) reported a survey where nearly three-quarters of the respondents said that they did not feel comfortable using their credit cards for online purchases. Consumers who are very highly concerned about protecting their privacy online may realize that even if they do not voluntarily submit any personal information to a Website, information is still exchanged between the consumers' client computers and the host server of the Website. The information exchanged includes the client machine's IP address (leading to the identification of the site user's location), and details of the specific areas of the Website that have been visited. Some Websites install software (known as "spyware") on client machines without the users' knowledge and consent. This software monitors the users' Web surfing activities and provides the information to a specific server (Staples, 2004). While the planting of spyware without the user's awareness and consent is illegal, many legitimate Websites install small files called "cookies" on user's hard drives for relatively benign purposes, such as letting the user personalize the Website, identifying registered users of a Website, recall stored shopping cart information at e-commerce sites, etc. Although legitimate Websites install cookies only with the user's permission (typically stated in their privacy policy), and they can be configured to run on Web browsers only under the user's own settings, the cookies are normally executed without any user action (Strauss and Frost, 2009). This feature is startling to Internet users who are extremely concerned about online privacy, and may feel that they could be unknowingly and involuntarily disclosing sensitive information while online. To protect their privacy, these consumers may be unwilling to use the Internet altogether in extreme cases.

Considering these three possible outcomes depending on the consumers' degree of concern about online privacy, we propose our final three research hypotheses:

H8: Indian consumers' online privacy concerns are negatively related to their willingness to provide personal information online.

H9: Indian consumers' online privacy concerns are negatively related to their participation in e-commerce transactions.

H10: Indian consumers' online privacy concerns are negatively related to their willingness to use the Internet.

\section{RESEARCH METHOD}

\section{Construct Operationalization}

The measures used to operationalize the constructs were adapted from relevant prior studies that explored 
some of the individual factors influencing online privacy concerns (Dinev and Hart, 2004; Dinev and Hart, 2006a; Dinev and Hart, 2006b; Sheehan and Hoy, 2000; Bellman et al., 2004; Culnan and Armstrong, 1999). Multi-item measures were established for the following variables: perceived vulnerability to unauthorized online personal data collection and use of such data (VULNER, 6 items); perceived ability to control the manner in which personal information is collected and used online (CONTROL, 4 items); Internet literacy (INTLIT, 4 items); Social awareness (SOCAWARE, 6 items); online privacy concerns (PRIVCON, 4 items); willingness to provide personal information online (WILINFO, 3 items), willingness to participate in e-commerce (WILECOM, 3 items); and the willingness to use the Internet (WILUSE, 2 items). For each scale item, survey respondents were asked to indicate, on a 7-point Likert scale, their perception regarding a statement describing the relevant variable.

\section{Sampling Frame}

Internet users in several metropolitan cities across India were given an online survey that included the multi-item scales to measure the study variables described above. The respondents were randomly selected from the online consumer panel of a major market research company. Altogether, 201 completed surveys were received. Of the 201 respondents, $83(41.3 \%)$ were female. The average age of the respondents was 34.9 years, and $181(90 \%)$ respondents were college graduates or beyond. The average time spent online by the respondents was 25.8 hours per week.

\section{RESULTS}

\section{Measurement of Scale Properties}

After the responses were compiled, the reliability of each multi-item measure was assessed via calculating Cronbach's coefficient alpha. The Cronbach's alphas and the descriptive statistics for the eight measures used in the study are presented in Table 1. The scale reliabilities were found to be satisfactory, considering the relatively small number of items for each measure (Churchill, 1979).

Table 1

Descriptive Statistics of the Measures $(\mathrm{N}=201)$

\begin{tabular}{|l|c|c|c|c|}
\hline \multicolumn{1}{|c|}{ Measure } & $\begin{array}{c}\text { Number } \\
\text { of Items }\end{array}$ & $\begin{array}{c}\text { Reliability } \\
\text { (Cronbach's Alpha) }\end{array}$ & $\begin{array}{c}\text { Mean } \\
\text { (Value range 1-7) }\end{array}$ & $\begin{array}{c}\text { Standard } \\
\text { Deviation }\end{array}$ \\
\hline Online privacy concerns (PRIVCON) & 4 & .878 & 5.08 & 1.49 \\
\hline Perceived vulnerability (VULNER) & 6 & .925 & 4.20 & 1.70 \\
\hline Perceived ability to control (CONTROL) & 4 & .788 & 5.58 & 1.17 \\
\hline Internet literacy (INTLIT) & 4 & .741 & 5.56 & 1.14 \\
\hline Social awareness (SOCAWARE) & 6 & .846 & 3.38 & 1.11 \\
\hline $\begin{array}{l}\text { Willingness to provide personal information } \\
\text { (WILINFO) }\end{array}$ & 3 & .629 & 4.56 & 1.42 \\
\hline $\begin{array}{l}\text { Willingness to participate in e-commerce } \\
\text { (WILECOM) }\end{array}$ & 3 & .765 & 4.43 & 1.98 \\
\hline Willingness to use the Internet (WILUSE) & 2 & .881 & 4.82 & 1.53 \\
\hline
\end{tabular}

\section{Tests of Hypotheses}

To test hypotheses $\mathrm{H} 1$ and $\mathrm{H} 2$, a regression analysis was done, with consumers' online privacy concerns (PRIVCON) as the dependent variable, and perceived vulnerability (VULNER) and perceived ability to control (CONTROL) as the independent variables. The results are indicated in Table 2. The overall regression model with the two predictor variables was found to be statistically significant $(\mathrm{F}=66.51$ with 2 degrees of freedom, $\mathrm{p}<.001)$, with $\mathrm{R}^{2}=.402$. Both predictor variables were found to significantly affect the online privacy concerns as well. As hypothesized, perceived vulnerability was positively related (standardized beta-coefficient estimate $=.430, \mathrm{t}=7.68$, $\mathrm{p}<.001$ ), and perceived ability to control was negatively related (standardized beta-coefficient estimate $=-.391, \mathrm{t}=$ $-6.98, \mathrm{p}<.001)$ to online privacy concerns. 
Table 2

Regression Predicting Indian Consumers' Online Privacy Concerns (PRIVCON)

\begin{tabular}{|c|c|c|}
\hline $\begin{array}{l}\text { Number of Observations }=201 \\
\mathrm{R}^{2}=.402 \\
\text { Overall } \mathrm{F}=66.51 \text {, d.f. }=2, \mathrm{p}<.001\end{array}$ & & \\
\hline $\begin{array}{c}\text { Predictor Variable } \\
\end{array}$ & Standardized Coefficient Estimate & t-Value (Probability of $t$ ) \\
\hline Intercept & 0.00 & $1.72(\mathrm{p}=.087)$ \\
\hline Perceived vulnerability (VULNER) & .430 & $7.68(\mathrm{p}<.001)$ \\
\hline Perceived ability to control (CONTROL) & -.391 & $-6.98(\mathrm{p}<.001)$ \\
\hline
\end{tabular}

Hypotheses H3, H4, and H5 were tested via a regression analysis, with perceived vulnerability (VULNER) as the dependent variable, and perceived ability to control (CONTROL), Internet literacy (INTLIT), and social awareness (SOCAWARE) as the independent variables. The results are reported in Table 3.

Table 3

Regression Predicting Indian Consumers' Perceived Vulnerability (VULNER)

\begin{tabular}{|c|c|c|}
\hline \multicolumn{3}{|l|}{$\begin{array}{l}\text { Number of Observations }=201 \\
\mathrm{R}^{2}=.208 \\
\text { Overall } \mathrm{F}=4.67, \text { d.f. }=3, \mathrm{p}<.01\end{array}$} \\
\hline Predictor Variable & Standardized Coefficient Estimate & t-Value (Probability of $t$ ) \\
\hline Intercept & 0.00 & $1.95(\mathrm{p}=.052)$ \\
\hline Perceived ability to control (CONTROL) & -.176 & $-2.66(\mathrm{p}<.01)$ \\
\hline Internet literacy (INTLIT) & -.169 & $-2.49(\mathrm{p}<.01)$ \\
\hline Social awareness (SOCAWARE) & .097 & $1.30(\mathrm{p}=.19)$ \\
\hline
\end{tabular}

As seen from Table 3, the overall regression model was statistically significant at the $\mathrm{p}<.01$ level $(\mathrm{F}=4.67$ with 3 degrees of freedom), with $\mathrm{R}^{2}=.208$. Perceived ability to control had a significant negative impact on perceived vulnerability (standardized beta-coefficient estimate $=-1.76, \mathrm{t}=-2.66$ ) at the $\mathrm{p}<.01$ level. Internet literacy also had a significantly negative impact on perceived vulnerability (standardized beta-coefficient estimate $=-.169$, $\mathrm{t}=-2.49$ ), again at the $\mathrm{p}<.01$ level. No significant impact of social awareness was found on perceived vulnerability, however (standardized beta-coefficient estimate $=.097, \mathrm{t}=1.30, \mathrm{p}=.19$ ). Therefore, hypotheses H3 and H4 were supported, while hypothesis H5 was not supported.

A regression analysis with perceived ability to control (CONTROL) as the dependent variable, and Internet literacy (INTLIT) and social awareness (SOCAWARE) as the independent variables was carried out to test hypotheses H6 and H7. The results are reported in Table 4. The overall regression model came out to be statistically significant at the $\mathrm{p}<.001$ level $\left(\mathrm{F}=32.62\right.$, with 2 degrees of freedom). The $\mathrm{R}^{2}$ value obtained was .248 . Internet literacy was found to positively impact the perceived ability to control (standardized beta-coefficient estimate $=.376, \mathrm{t}=5.74, \mathrm{p}<.001$ ). Social awareness was also found to positively impact the perceived ability to control (standardized beta-coefficient estimate $=.224, \mathrm{t}=3.43, \mathrm{p}<.001$ ). Therefore, both hypotheses H6 and H7 were supported.

Table 4

Regression Predicting Indian Consumers' Perceived Ability to Control (CONTROL)

\begin{tabular}{|c|c|c|}
\hline $\begin{array}{l}\text { Number of Observations }=201 \\
\mathrm{R}^{2}=.248 \\
\text { Overall } \mathrm{F}=32.62 \text {, d.f. }=2, \mathrm{p}<.00\end{array}$ & & \\
\hline Predictor Variable & Standardized Coefficient Estimate & t-Value (Probability of $t$ ) \\
\hline Intercept & 0.00 & $4.92(\mathrm{p}<.001)$ \\
\hline Internet literacy (INTLIT) & .376 & $5.74(\mathrm{p}<.001)$ \\
\hline Social awareness (SOCAWARE) & .224 & $3.43(\mathrm{p}<.001)$ \\
\hline
\end{tabular}


The hypotheses regarding the outcomes of Indian consumers' online privacy concerns (H8 through H10) were tested by correlating the consumers' privacy concerns (PRIVCON) with the three possible outcomes: willingness to provide personal information online (WILINFO), willingness to participate in e-commerce (WILECOM), and willingness to use the Internet (WILUSE). The Pearson correlation coefficient between online privacy concerns and willingness to provide personal information online was -.504 (significant at the $p<.001$ level), thus supporting the hypothesized negative relationship between the two variables (H8). The Pearson correlation coefficient between online privacy concerns and the willingness to participate in e-commerce was also negative (-.269) and significant at the $\mathrm{p}<.001$ level. This provided support for hypothesis H9. No support was obtained for hypothesis H10, however, as the Pearson correlation coefficient between online privacy concerns and the willingness to use the Internet came out to be -.105 , which was not statistically significant ( $\mathrm{p}=.138$ ).

\section{DISCUSSION AND MANAGERIAL IMPLICATIONS}

The results of the tests of hypotheses are summarized in Table 5 below. It is seen that the empirical data provided support for eight of the ten hypotheses that were tested.

Table 5

Summary Results of the Tests of Hypotheses

\begin{tabular}{|l|l|l|}
\hline \multicolumn{2}{|c|}{ Hypothesis } & \multicolumn{1}{c|}{ Result } \\
\hline H1 & Perceived vulnerability $\rightarrow+$ Online privacy concerns & Supported $(\mathrm{p}<.001)$ \\
\hline H2 & Perceived ability to control $\rightarrow-$ Online privacy concerns & Supported $(\mathrm{p}<.001)$ \\
\hline H3 & Perceived ability to control $\rightarrow-$ Perceived vulnerability & Supported $(\mathrm{p}<.01)$ \\
\hline H4 & Internet literacy $\rightarrow-$ Perceived vulnerability & Supported $(\mathrm{p}<.01)$ \\
\hline H5 & Social awareness $\rightarrow+$ Perceived vulnerability & Not supported \\
\hline H6 & Internet literacy $\rightarrow+$ Perceived ability to control & Supported $(\mathrm{p}<.001)$ \\
\hline H7 & Social awareness $\rightarrow+$ Perceived ability to control & Supported $(\mathrm{p}<.001)$ \\
\hline H8 & Online privacy concerns $\rightarrow-$ Willingness to provide personal information online & Supported $(\mathrm{p}<.001)$ \\
\hline H9 & Online privacy concerns $\rightarrow-$ Willingness to participate in e-commerce & Supported $(\mathrm{p}<.001)$ \\
\hline H10 & Online privacy concerns $\rightarrow-$ Willingness to use the Internet & Not supported \\
\hline
\end{tabular}

The study results suggest that online privacy concerns of Indian consumers could be reduced by reducing their perceived vulnerability to information misuse and its consequences, and by increasing their perceived ability to control the collection and use of sensitive personal information online (hypotheses H1 and H2). The perceived vulnerability itself could also be reduced (thus reducing the privacy concerns, in turn) by increasing the consumers' perceived ability to control information collection and usage (hypothesis H3), and by increasing their level of Internet literacy (hypothesis H4) . The perceived ability to control can be positively impacted by the consumers' level of Internet literacy and their level of awareness of social issues involving Internet usage (hypotheses H6 and H7). Online marketers targeting the Indian audience should, therefore, make efforts to increase the consumers' Internet literacy by educating them about the options available for protecting private information. For example, they can post information on their Websites about specific software (e.g., firewalls, browser security fixes) or procedures (e.g., setting browser configurations to prevent tracking cookies being implanted without the user's permission) that may alleviate privacy concerns by increasing the perceived control and reducing the perceived vulnerability (Spiekermann, Grossklags, and Berendt, 2001). Given the relatively high educational achievements of Internet users in India (over $90 \%$ in our study sample were college graduates or beyond), such information should be easily understood by the majority of people using the Internet and, therefore, should be effective.

In our study, social awareness was not found to directly impact the consumers' perceived vulnerability to unauthorized information gathering and use (hypothesis H5), but a heightened level of social awareness did positively affect the consumers' perceived ability to control the collection and use of personal information (hypothesis H7), and therefore, could be said to negatively influence online privacy concerns (following hypothesis H2) indirectly. Internet marketers can seek to increase the social awareness of consumers by posting a comprehensive privacy policy prominently on the home page of their Website (Hui, Teo, and Lee, 2007). A key element is to convince the consumers regarding the procedural fairness in the collection and use of personal data, 
and increasing the consumers' trust in the Website (Culnan and Armstrong, 1999). Specific measures that marketers may implement include promoting the reputation and legitimacy of the company requesting information (Andrade, Kaltcheva, and Weitz, 2002), displaying third-party privacy seals such as VeriSign, TrustE, etc. (these are available in India) on their Websites (Hui, Teo, and Lee, 2007). It is also prudent for online marketers not to ask for more information than is absolutely necessary for effecting e-commerce transactions.

Our study shows that when Indian consumers are highly concerned with their online privacy, they are less willing to disclose personal information online and were less inclined to participate in e-commerce transactions (hypotheses $\mathrm{H} 8$, and $\mathrm{H} 9$, respectively). These negative consequences of consumers' online privacy concerns are not acceptable to marketers who rely on enhancing their marketing strategies (consumer profiling, better targeting, etc.) by collecting and analyzing individual-level data, or who offer e-commerce transactions on their Websites. To reduce the probability of these negative outcomes, marketers will need to address the antecedents of online privacy concerns and alleviate those concerns. We found that online privacy concerns did not negatively impact the Indian consumers' willingness to surf the Internet altogether (hypothesis H10). This is an encouraging sign, as the average level of online privacy concern among our sample was moderately high (5.08 on a 7-point scale, as indicated in Table 1). The demographic information revealed that our respondents spent an average of 25.8 hours on the Internet. We also found that $75.7 \%$ of the respondents (152 out of 201) would read the "privacy policy" posted on a Website before providing any personal information to the site, or before conducting any financial transaction at the site. This suggests that if online marketers choose to offer comprehensive information about protecting the site visitors' privacy, Indian consumers are more than likely to read that information and that would certainly help in reducing their privacy concerns and encouraging them to provide personal information online, and participate in e-commerce.

\section{CONCLUSION}

The online market in India is substantial, with 81 million people currently using the Internet (Internet World Stats, 2010), and the growth potential is huge, considering that only about 7 percent of the country's 1.17 billion people are currently online. We presented the results of an empirical test to investigate the influence of specific factors on the online privacy concerns of consumers in India, and the interrelationships among those factors. We also identified the undesirable outcomes of Indian consumers' online privacy concerns on Internet marketers, e.g., reluctance to disclose personal information online, and reluctance to engage in e-commerce transactions. Online marketers targeting the Indian audience need to understand the influencing factors and address them appropriately (as outlined in the managerial implications), so that consumers' online privacy concerns are reduced and they are willing to disclose personal information on the Internet, and participate in e-commerce. This is critical, because marketers simply cannot afford to ignore the huge potential of the Indian online market.

\section{AUTHOR INFORMATION}

Soumava Bandyopadhyay is a professor of marketing at Lamar University, U.S.A. His areas of research interest include Internet-based marketing, global marketing, and channels of distribution.

\section{REFERENCES}

1. Andrade, E.B., Kaltcheva, V., \& Weitz, B. (2002). Self-Disclosure on the Web: The Impact of Privacy Policy, Reward, and Company Reputation. Advances in Consumer Research, 29, 350-353.

2. Bellman, S., Johnson, E.J., Kobrin, S.J., \& Lohse, G.L. (2004). International Differences in Information Privacy Concerns: A Global Survey of Consumers. The Information Society, 20, 313-324.

3. Basu, S. (2010). Policy-making, Technology and Privacy in India. The Indian Journal of Law and Technology, 6, 65-88.

4. Bickford, D.M. \& Reynolds, M. (2002). Activism and Service-Learning: Reframing Volunteerism as an Act of Dissent. Critical Approaches to Teaching, Literature, Language, Composition, and Culture, 8 (2), 229-252.

5. Budnitz, M. (1998). Privacy Protection for Consumer Transactions in Electronic Commerce: Why SelfRegulation is Inadequate. South Carolina Law Review, 49 (1), 847-886. 
6. Burn, J. \& Loch, K. (2001). The Societal Impact of the World Wide Web-Key Challenges for the $21^{\text {st }}$ Century. Information Resources Management Journal, 14 (4), 4-14.

7. Caruso, D. (1998). The Law and the Internet Beware. Columbia Journalism Review, 37 (1), $57-61$.

8. Churchill, G.A., Jr. (1979). A Paradigm for Developing Better Measures of Marketing Constructs. Journal of Marketing Research, 16 (February), 64-73.

9. Culnan, M. \& Armstrong, P. (1999). Information Privacy Concerns, Procedural Fairness, and Impersonal Trust: An Empirical Investigation. Organization Science, 10 (1), 104-115.

10. Dinev, T. \& Hart, P. (2004). Internet Privacy Concerns and Their Antecedents-Measurement Validity and a Regression Model. Behavior and Information Technology, 23 (6), 413-422.

11. Dinev, T. \& Hart, P. (2006a). Internet Privacy Concerns and Social Awareness as Determinants of Intention to Transact. International Journal of Electronic Commerce, 10 (2), 7-29.

12. Dinev, T. \& Hart, P. (2006b). Privacy Concerns and Levels of Information Exchange: An Empirical Investigation of Intended E-Service Use. E-Service Journal, 6 (1), 25-59.

13. Fletcher, K. (2003). Consumer Power and Privacy: The Changing Nature of CRM. International Journal of Advertising, 22, 249-272.

14. Gupta, A. (2010). Balancing Online Privacy in India. The Indian Journal of Law and Technology, 6, 43-64.

15. Graeff, T.R. \& Harmon, S. (2002). Collecting and Using Personal Data: Consumers' Awareness and Concerns. The Journal of Consumer Marketing, 19, 302-318.

16. Hui, K., Teo, H., \& Lee, S. T. (2007). The Value of Privacy Assurance: An Exploratory Field Experiment. MIS Quarterly, 31 (1), 19-33.

17. Internet World Stats (2010). Online at http://www.internetworldstats.com

18. Nam, C., Song, C., Lee, E., \& Park, C. (2006). Consumers' Privacy Concerns and Willingness to Provide Marketing-Related Personal Information Online. Advances in Consumer Research, 33, 212-217.

19. Papazafeiropoulou, A. \& Pouloudi, A. (2001). Social Issues in Electronic Commerce: Implications for Policy Makers. Information Resources Management Journal, 14 (4), 24-32.

20. Patel, K., Vescovi, V., \& Rocca, A. (2010). Profiling the Facebooks of the World. Advertising Age, 81 (24), 6.

21. Raab, C.D. \& Bennet, C.J. (1998). The Distribution of Privacy Risks: Who Needs Protection? The Information Society, 14 (4), 253-262.

22. Rice, R.E., McCreadie, M., \& Chang, S.L. (2001). Accessing and Browsing Information and Communication. Cambridge, MA: The MIT Press.

23. Rindfleish, T.C. (1997). Privacy, Information Technology, and Healthcare. Communications of the ACM, 40, 92-100.

24. Rust, R.T., Kannan, P.K., \& Peng, N. (2002). The Customer Economics of Internet Privacy. Journal of the Academy of Marketing Science, 30, 455-464.

25. Saunders, K. \& Zucker, B. (1999). Contracting Identity Fraud in the Information Age: The Identity Theft and Assumption Deterrence Act. International Review of Law, Computers, and Technology, 13 (2), 183192.

26. Sheehan, K.B. \& Hoy, M.G. (2000). Dimensions of Privacy Concern Among Online Consumers. Journal of Public Policy and Marketing, 19 (1), 62-73.

27. Sheth, N. (2008). India Start-Ups Look to Home: As U.S. Economy Slows, Firms Tailor Web Sites for Local Consumers. Wall Street Journal, Eastern Edition, March 27, B7.

28. Spiekermann, S., Grossklags, J., \& Berendt, B. (2001). E-Privacy in $2^{\text {nd }}$ Generation E-Commerce. Privacy Preferences versus Actual Behavior. In Proceedings of EC'01: Third ACM Conference on Electronic Commerce. New York: Association for Computing Machinery, 38-47.

29. Staples, B. (2004). The Battle Against Junk Mail and Spyware on the Web. New York Times, January 3.

30. Strauss, J., \& Frost, R. (2009). E-Marketing. Upper Saddle River, NJ: Pearson Prentice Hall.

31. Wang, H., Lee, M.K.O., \& Wang, C. (1998). Consumer Privacy Concerns About Internet Marketing. Communications of the ACM, 41, 63-70. 